\title{
Permanganate - Based Hybrid Nano-Conversion Coating on Aluminium
}

\author{
Makanjuola Oki ${ }^{1, a^{*}}$, Adeolu Adesoji Adediran ${ }^{1, b}$ \\ ${ }^{1}$ Department of Mechanical Engineering, Landmark University, PMB 1001, Omu-Aran, \\ Kwara State, Nigeria \\ a*makanjuola.oki@Imu.edu.ng, badediran.adeolu@Imu.edu.ng
}

\begin{abstract}
Keywords: Adhesion; SEM; Permanganate; Glycerol; Hybrid coating; Pitting
\end{abstract}
\begin{abstract}
The present work investigates a hybrid nano-coating based on permanganate/ fluoride/glycerol conversion coating solution on aluminium alloy AA6061. From gravimetric studies, the nano-coatings formed on aluminium alloy by immersion procedures developed rapidly at a rate which decreased with time of treatment and was about $5 \mathrm{gm}^{-2}$ after a period of three minutes. The morphology of the coating from scanning electron microscopic (SEM) examinations revealed randomly shaped coating materials with mud cracking patterns, characteristics of dried out coatings derived from gel-like materials. Analyses of the coating with the energy dispersive analysis of X-ray spectroscopy (EDS) attachment in the SEM revealed the composition as compounds of aluminium, oxygen and manganese, probably hydrated. The corrosion resistance of the coating outperformed 'bare' aluminium alloy specimens exposed to both natural and $3.5 \%$ sodium chloride solution environments. The coating improved the paint adhesion characteristics of the substrate aluminium alloy. Macro and micro features developed on the substrate aluminium are anchor points which improved the adhesion of subsequently applied lacquer.
\end{abstract}

\section{Introduction}

Automobile customers' demand for higher performance, more luxury and safety features signaled the development of lightweight and hence more energy efficient vehicles. These led to the introduction of aluminium and its alloys into the vehicle manufacturing industry to achieve considerable weight reductions with no losses in strength and stiffness. However, these changes in the choice of materials and body structures present significant challenges with respect to methods of joining and finishing of automobile parts. In these respects, conversion coatings offer several advantages such as improved corrosion resistance and adhesion of paint/adhesives to aluminium and its alloys. The successful use of chromate conversion coatings in the last five decades have demonstrated that superior strength can be acquired, even when the coated structure would be exposed to corrosive environments [1]. However, several protocols in the last two decades have limited the use of carcinogens like volatile organic compounds (VOCs) and chromates in various applications. In view of these shortcomings, several authors [2-5] have researched into alternatives to chromates using various transition metal compounds without much success in terms of corrosion resistance. Chromates demonstrated superior corrosion resistance over these alternatives. The searches for alternatives to chromates have progressed far and wide while other researchers have examined sol-gel formulations such as aluminium-based materials by Oubaha et al. [6] and silanolbased nano-composite by Gonzalez et al. [7] with much success recorded in terms of improved paint adhesion characteristics which compared favourably with the chromates. Nonetheless, some of these formulations and processes have been patented [8] but their applications have been limited to the lower technical end of the metal finishing markets while in the high technical end such as in the aerospace industry as well as military hardware, chromates are still preferentially employed [9]. In order to make the use of chromates more acceptable to the metal finishing industries, non-rinse chromate formulations were developed [10,11]. Addition of organic compounds containing hydroxyl groups to chromate baths modified the surface features of the traditional coating where the usual mud-crack morphology was obliterated and it became unnecessary to give a final water rinse to objects treated in such baths [10]. In addition, the coatings dried faster than the traditional chromate coatings. Thus, from environment point of view, interaction of the workforce in the metal 
finishing line with chromate coating solutions was reduced to the barest minimum as the final rinse stage was removed with its attendant effluents which contain chromium (VI) species. These would have been treated at a cost prior to discharge to the outside environment. Thus, it achieved reduction in the costs of production by the removal of both effluent treatment and high temperature drying prior to application of final organic finishes. In view of the limited successes encountered in the search for viable alternatives to chromates, the current investigation examined permanganate with variable valences as a precursor coating material of interest which may also act as cathodic inhibitors at breached areas of the coating where the substrate may be exposed albeit, transiently.

\section{Materials and Methods}

Spade like electrodes were made from sheet of aluminium alloy AA6061. These electrodes were etched in $10 \%$ sodium hydroxide solution, rinsed in water prior to de-smutting in $50 \% \mathrm{v} / \mathrm{v}$ nitric acid solution for three minutes each and then rinsed in water. Electrodes, prepared in the aforementioned manner were immersed in a solution of $4 \mathrm{~g} / 1 \mathrm{KMnO} 4,1 \mathrm{~g} / 1 \mathrm{NaF}$ and $5 \mathrm{ml} / 1$ glycerol made up to 1 liter with water, at $30{ }^{\circ} \mathrm{C}$ for several periods of time ranging from 30 secs to 600 secs. The $\mathrm{pH}$ of the solution was 7.9 as obtained from JENWAY, Model $3505 \mathrm{pH}$ Meter. All chemicals used were of laboratory or industrial grades. Triplicate specimens treated for various times in the permanganate/fluoride/glycerol coating solutions were examined in scanning electron microscope, SEM, Phenom proX, model MVE0224651193, operated at $15 \mathrm{Kev}$. The elemental compositions of the coatings were obtained from the EDS attachment in the microscope. Triplicate specimens treated for $180 \mathrm{~s}$ in the coating solutions were exposed in upright positions to the natural environment in the North Central part of Nigeria for $500 \mathrm{~h}$ with three untreated aluminum alloy specimens exposed likewise. These were visually examined regularly. Triplicate sets of specimens were likewise treated in the coating solution for $180 \mathrm{~s}$. These were further coated with a nitrocellulose lacquer by immersing the spade like end of the pretreated specimens as near vertical as possible in $100 \mathrm{ml}$ of the lacquer for $60 \mathrm{~s}$ and withdrawn as immersed, allowed to dry for $24 \mathrm{~h}$ prior to further examinations. Triplicate sets of untreated aluminum and pretreated specimens as well as those over coated with lacquer were cross-scratched, using Japanese industrial testing method (JISK5400, 1990) prior to exposure in near neutral 3.5\% NaCl solution for $170 \mathrm{~h}$. After the exposure period, transparent cellophane adhesive tapes were firmly applied on each of the specimens. The tapes were subsequently rapidly pulled from the substrates. The surfaces were examined to appraise the mode(s) of coating failure by optical microscopy and in the SEM with analyses performed in the EDS attachment of the SEM.

\section{Results and Discussions}

\section{Coating development}

From visual examinations the specimens immersed in the permanganate/fluoride/glycerol coating solution showed changes in colour from the initial lustrous metallic appearance to progressively dark golden yellow colorations with increase in the time of immersion. On surface value, this implied formation and development of coatings in the conversion coating bath. The formation and development of permanganate coating on aluminium probably followed "the substrate activation/coating materials deposition" model reported for chromate conversion coatings [12-15] which will involve the activation of aluminum by fluoride species in solution thus,

$$
\mathrm{Al} \stackrel{\mathrm{F}^{-}}{\rightarrow} \mathrm{Al}^{3+}+3 \mathrm{e}^{-}
$$

The 3 electrons generated during the activation of aluminum, an anodic reaction, were then taken up by permanganate species which were reduced to manganate in the cathodic half of the redox reactions. These Mn (IV) species, at concentrations equal to/or slightly above their established equilibrium constants, were deposited on the aluminium substrates as probably hydrated 
oxide/hydroxides of Manganese which may be contaminated with permanganate ions in the coating solution as well as aluminum species/oxides/hydroxides formed from $\mathrm{Al}^{3+}$ generated in equation, 1 . These species may as well be adsorbed and/or occluded within the developing coatings.

$$
2 \mathrm{H}_{2} \mathrm{O}+\mathrm{MnO}_{4}^{-}+3 \mathrm{e}^{-} \rightarrow \mathrm{MnO}_{2}+4 \mathrm{OH}^{-}
$$

Another school of thought [11] deposed that fluoride in conversion coating baths thinned down the initial oxide skin on aluminium alloy to the extent that electrons' tunneling was encouraged to occur at the metal/oxide interface. Such will lead to the reduction of permanganate species to manganese(IV) with their eventual deposition as their oxides; the conversion coating. The anodic reaction in this instance would be the re-deposition of $\mathrm{Al}^{3+}$ as aluminium oxide.

Figure 1 displays the coating weight versus time of immersion for aluminium alloy specimens in permanganate/glycerol conversion coating bath. The rate of coating growth was rapid initially, however, the rate decreased with increase in immersion time. This was envisaged as the initial coating materials deposited on the specimens would initially constitute barriers to further coating growth [16, 17]. However, as observed by Furneaux et al. [13] Abd Rabbo et al. [12] and Asami et al. [18] further coating growth beyond the initial rapid deposition of coating materials proceeded at the metal/coating interface with the creation of pathways within the coating materials. Thus coating solution species come in contact with the substrate although at a reduced rate with continued growth of the coating.

\section{Surface Morphology and Composition.}

The surface morphology for a specimen treated for $180 \mathrm{~s}$ in the permanganate/glycerol coating bath is displayed in Fig. 2a and it portrays a typical surface morphology for specimens treated in the coating bath for various times. The surface is comprised of variously shaped coating materials formed along with mud-crack patterns derived from shrinkage stresses associated with drying out of gel-like materials. Such randomly shaped and cracked surface features have been suggested to be anchor sites for subsequently applied organic coatings with attendant improvement in paint adhesion characteristics of conversion coated substrates [19]. However other researchers believe that in addition to these anchor sites, bonds formation between organic coatings and species in conversion coatings play significant roles in the improvement of paint adhesion properties of conversion coated substrates [20]. Also, in an earlier study it was suggested that roughness at microscopic level imparted on conversion coated surfaces provided interlocking features with organic coating molecules which played added significant roles in adhesion improvement properties of conversion coated aluminium substrates [21].

The coating materials as revealed through analyses with the EDS attachment in the SEM are composed of manganese, aluminium and oxygen compounds, Fig. 2b, probably hydrated as the materials were derived from gel-like materials as noted earlier. Aluminium may be derived from the coating as compounds formed from $\mathrm{Al}^{3+}$ generated during activation by $\mathrm{F}^{-}$species as well as from the substrate which is an aluminium alloy. Oxygen and manganese will generally be derived from the coating materials in addition to other contaminants such as $\mathrm{K}$ and $\mathrm{S}$. These analyses are supported by the findings of Yogannadan et al. [22]; Guixiang et al. [23]; Oki et al. [24] who, with the use of XRD, XPS and SEM/EDS respectively concluded that PCCs are composed of various oxides of Manganese.

\section{Corrosion and Adhesion Performance}

All the specimens conversion coated in PCC baths were superior in performance to the 'bare' specimens on which incipient pits were resolvable with the naked eyes in addition to mounds of corrosion products which appeared whitish under lacquer coatings. There were no obvious incidents of pitting on both the 'bare' conversion coated and those with top coatings of lacquer after the time of exposure. For specimens immersed in $3.5 \%$ sodium chloride solution, 'bare' aluminium 
specimens with and without lacquer coatings showed severe pitting corrosion over the immersion period employed. A typical example is displayed in Fig. 3, the scanning electron micrograph of the unscratched regions of 'bare' aluminium specimen with a top coating of lacquer. The micrograph portrayed a relatively large pit, marked $\mathrm{X}$ at the top of the micrograph with corrosion products at the bottom of the micrograph, marked, Y.

The corrosion products, likely to have migrated from within the pit, where active pitting corrosion occurred are composed of hydrated aluminium hydroxides and/or oxides which were initially gellike and developed cracked morphologies during drying out. The EDS analysis in the region revealed the presence of $\mathrm{Al}, \mathrm{O}, \mathrm{Cl}$ and $\mathrm{Na}$ which indicated the presence of aluminium products contaminated or otherwise with chlorides which are known pitting agents of aluminium and its alloys. On the other hand, the unscratched regions of the conversion coated specimen with a top coating of lacquer, displayed in Fig. 4, did not show pitted regions, however, a region at the top right corner of the micrograph, marked ' + ' revealed disaggregated materials which may be a flawed region of the composite conversion coating/lacquer where pitting corrosion may have initiated but propagation was hindered in one manner or the other. This phenomenon was not observed in the cases of 'bare' aluminium specimens.

EDS spectra of spot analysis at this region as presented in Fig. 4b, revealed the presence of aluminium, manganese, oxygen, potassium and chloride. $\mathrm{Mn}, \mathrm{Al}, \mathrm{O}$ are derived from the conversion coating whereas the presence of chloride implied its corrosive activities at the flaw in the coating which led to production of disaggregated materials in the region highlighted.

Another interesting feature which appeared as light materials at the top left hand corner of the micrograph in Fig. 4a, marked $\mathrm{K}$, are composed of $\mathrm{Al}, \mathrm{Mn}, \mathrm{O}$ and $\mathrm{Cl}$ as indicated by EDS analyses; they may likewise be pitting corrosion products which had plugged the entrance to a pit. The presence of reducible $\mathrm{MnO}_{4}{ }^{-}$in permanganate coatings had been established by Danilidis et al. [19]. Such anions in the vicinity of active pitting activities can effectively consume the electrons generated from the aluminium substrate to form $\mathrm{MnO}_{2}$ mixed with aluminium compounds to give rise to such features on the PCC coated aluminium specimen.

From the foregoing analyses, conversion coated specimens with top coating of lacquer outperformed its 'bare' aluminium counterpart in terms of corrosion resistance. As far as paint adhesion characteristic was concerned, paint delamination was not observed on the conversion coated specimens and the top coating of lacquer was not removed after the application of tape peeling tests. On the other hand, lacquer was easily removed from 'bare' aluminium specimens after exposure to sodium chloride solution over a period of $170 \mathrm{~h}$.

\section{Conclusions}

The hybrid permanganate/fluoride/glycerol conversion coating on aluminium alloy is composed of $\mathrm{Mn}, \mathrm{Al}$ and $\mathrm{O}$ compounds. Its cracked surface morphology appeared rough on a microscopic scale. The corrosion resistance and paint adhesion characteristics of the conversion coating/lacquer composite on aluminium alloy are superior to those of 'bare' aluminium alloy.

\section{Conflict of interest}

No conflict of interest

\section{Acknowledgement}

The authors acknowledge Department of Mechanical Engineering, Covenant University, Ota, Ogun State, Nigeria, for the use of SEM/EDS facilities. 


\section{Figure caption}

Figure 1: Graph of coating weight against time of immersion in potassium permanganate/fluoride/glycerol solution at $30^{\circ} \mathrm{C}$

Figure 2a and b: A representative SEM micrograph (a) with (b) EDS analysis of aluminium specimen treated for $180 \mathrm{~s}$ in Permanganate/fluoride/glycerol conversion coating bath at $30{ }^{\circ} \mathrm{C}$

Figure 3: Scanning electron micrograph of lacquer coated 'bare' aluminium immersed in 3.5\% $\mathrm{NaCl}$ solution for $170 \mathrm{~h}$ at $30^{\circ} \mathrm{C}$.

Figure 4 and b: (a) A representative Scanning electron micrograph and (b) EDS of conversion coated aluminium with a top coating of lacquer immersed in $3.5 \% \mathrm{NaCl}$ solution for $170 \mathrm{~h}$ at $30{ }^{\circ} \mathrm{C}$ after application of adhesion tests.

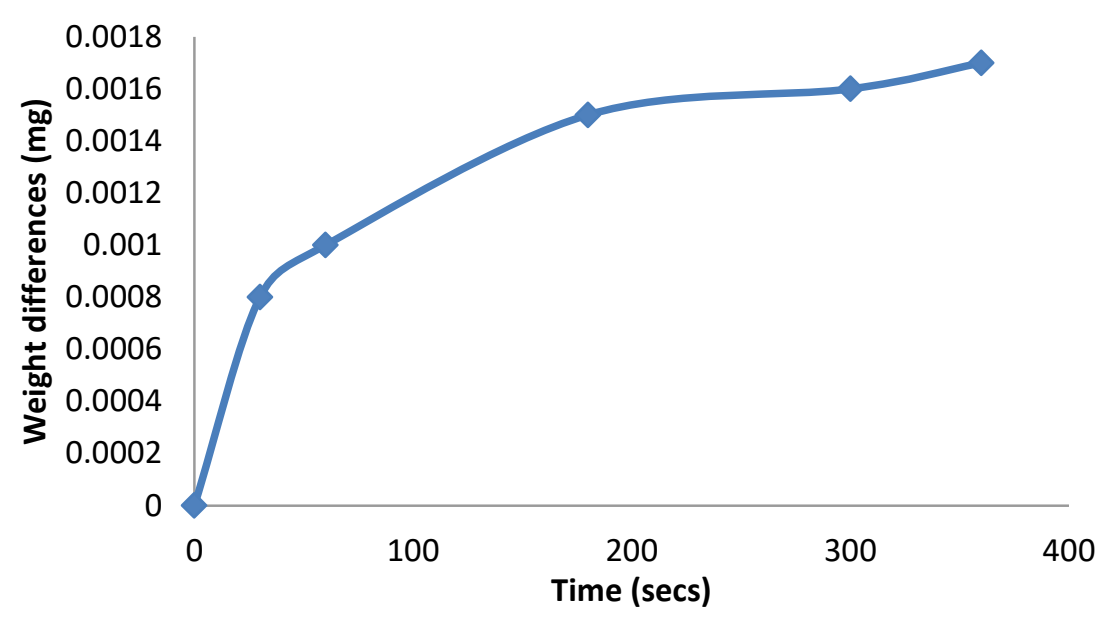

Fig. 1: Graph of coating weight against time of immersion in potassium Permanganate/fluoride/glycerol solution at $30{ }^{\circ} \mathrm{C}$

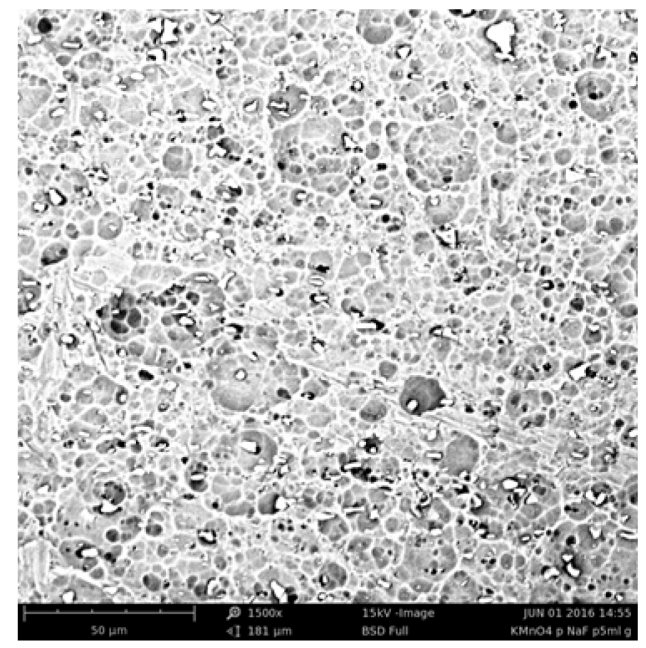

Fig. 2a: SEM micrograph of aluminium specimen treated for 180 seconds in

Permanganate/fluoride/glycerol conversion coating bath at $30{ }^{\circ} \mathrm{C}$ 


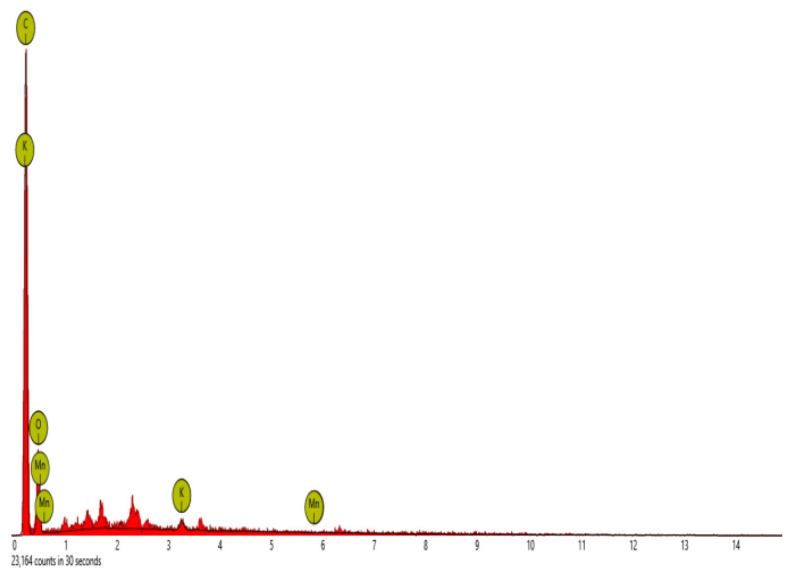

Fig. 2b: EDS analysis of aluminium specimen treated for 3 minutes in Permanganate/fluoride/glycerol conversion coating solution at $30{ }^{\circ} \mathrm{C}$

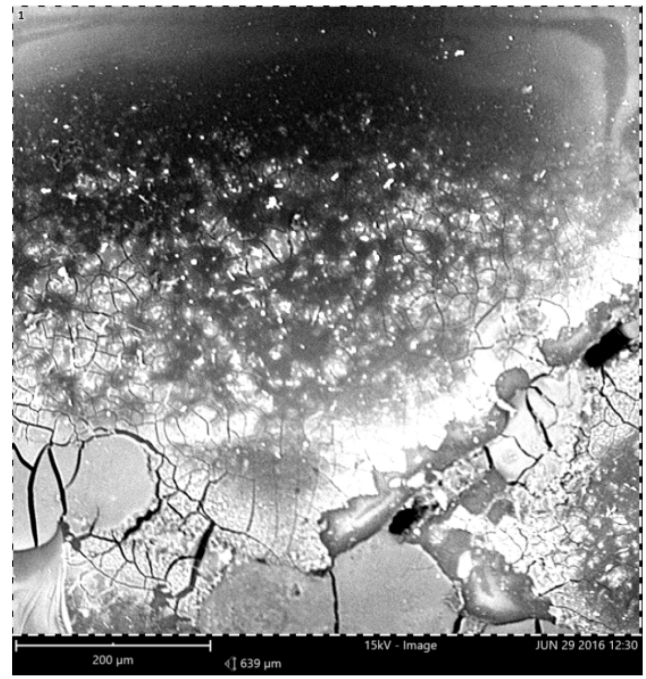

Fig. 3: Scanning electron micrograph of lacquer coated 'bare' aluminium immersed in 3.5\% $\mathrm{NaCl}$ solution for 170 hours at $30{ }^{\circ} \mathrm{C}$

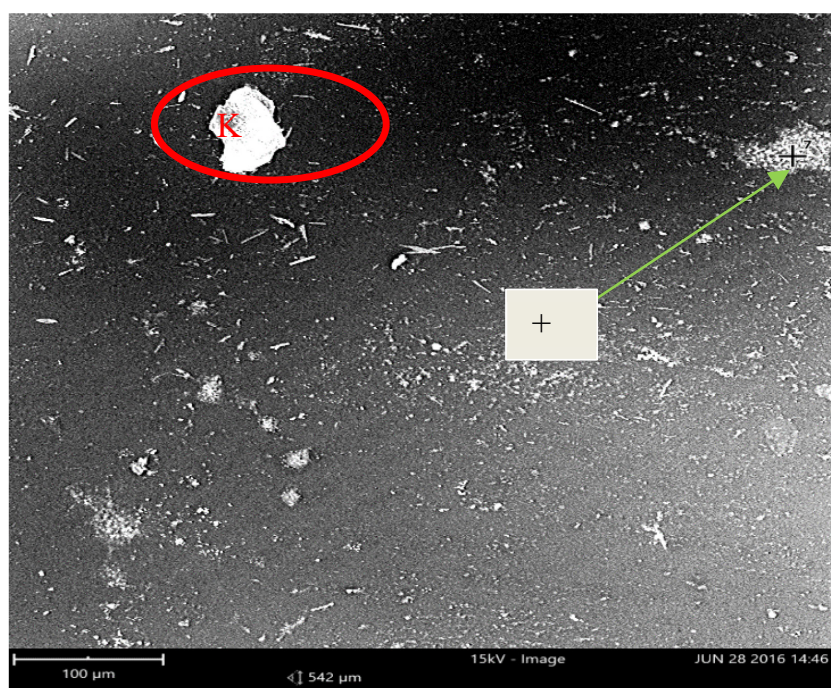

Fig.4a: Scanning electron micrograph of conversion coated aluminium with a top coating of lacquer after immersion in $3.5 \% \mathrm{NaCl}$ solution for $170 \mathrm{~h}$ at $30{ }^{\circ} \mathrm{C}$ after application of adhesion tests 


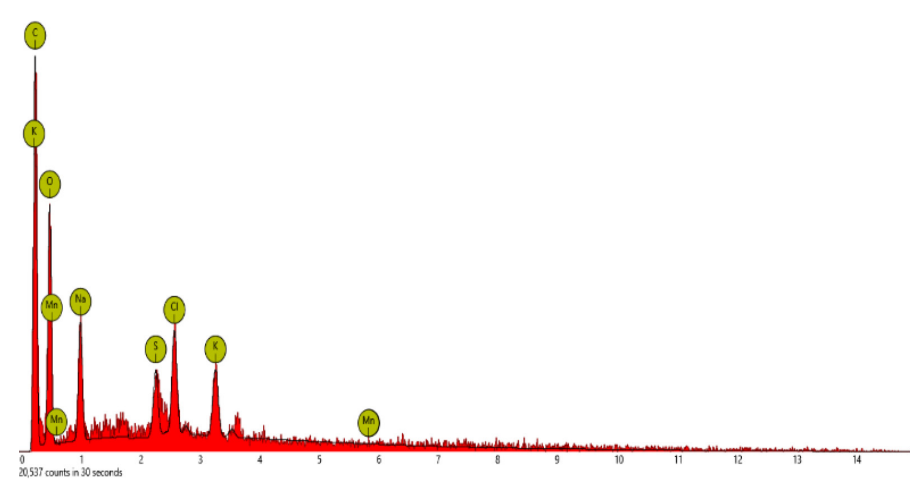

Fig. 4b: EDS analysis of conversion coated aluminium with a top coating of lacquer immersed in $3.5 \% \mathrm{NaCl}$ solution for $170 \mathrm{~h}$ at $30{ }^{\circ} \mathrm{C}$ after application of adhesion tests

\section{References}

[1] O. Lunder. Chromate free pretreatment of aluminium for adhesive bonding, $\mathrm{PhD}$ Thesis, Norges teknisk-naturvitenskapelige Universitet, 2003.

[2] S. Joshi, B.L. Treu, M.J. O'Keefe, W.H. Fahrenholtz, Characterization of cerium-based conversion coatings on Al 7075-T6 deposited from chloride and nitrate salt solutions. J. Electro. Soc. 158(3) (2011) 88-93.

[3] C.S. Liang, Z.F. Lv, Y.L. Zhu, S.A. Xu, Molybdate-based conversion treatment for improving the peeling strength between aluminum foil and polypropylene grafted with glycidyl methacrylate. Surf. Coat. Techn. 249 (2014)1-5.

[4] H.R. Asemani, P. Ahmadi, A.A. Sarabi, H. Eivaz Mohammadloo, Effect of zirconium conversion coating: Adhesion and Anti-corrosion properties of epoxy organic coating containing zinc aluminum polyphosphate (ZAPP) pigment on carbon mild steel. Prog. Org. coat. 94 (2016)18-27.

[5] M. Oki, Studies on chromium-free conversion coatings on Aluminium. J. Appl. Sci. Environ. Manag.11 (2007)187-190.

[6] M. Oubaha, P.C.R. Varma, B. Duffy, Z.M. Gasem, S.J. Hinder, Development of a novel hybrid aluminum-based sol-gel materials: Application to the protection of AA2024-T3 alloys in alkaline environment. Adv. Mater. Phy. Chem. 4 (2014) 75-84.

[7] E. Gonzalez, J. Pavez, I. Azocar, J.H. Zagal, X. Zhou, F. Melo, G.E. Thompson, M.A. Páez Silanol-based nano-composite coating for protection of AA-2024 aluminium alloy. Electr. Acta. 56 (2011) 7585-7595.

[8] R. Buchheit, U. S. Patent 7, 135,075 B2. (2006)

[9] N.N. Vovodin, V.N. Balbyshev, M.S. Donley, Investigation of corrosion protection performance of sol-gel coatings on AA2024T3. Prog. Org. coat. 52 (2005) 28-33.

[10] M. Oki, Functionalised chromate conversion coating. Patent number, NG/P/2013/755. (2014).

[11] G.E. Thomson, Conversion coatings TALAT Lecture series 5202, European Aluminium Association, (1994) pp. 1-9.

[12] M.F. Abd Rabbo, J.A. Richardson, G.C. Wood, A study of conversion coating development on aluminium in chromate/fluoride solutions using secondary ion mass spectrometry. Cor. Sci. 18 (1978) 117-123.

[13] R.C. Furneaux, G.E. Thompson, G.C. Wood, An electronoptical study of the conversion coating formed on aluminium in a chromate/fluoride solution. Cor. Sci.19 (1979) 63-71.

[14] M. Oki, E. Charles, Chromate conversion coating on Al/0.2\% Fe, Mater. Lett. 63 (2009)19901991.

[15] M. Oki, T.K. Oki, E. Charles, Chromate and chromate phosphate conversion coatings on aluminium, Arab. J. Sci. Eng. 37 (2012) 59-64.

[16] S.A. Kulinich, M. Farzaneh, X.W. Du, Growth of corrosion-resistant manganese oxide coatings on an aluminum alloy. Inorg. Mater. 43 (2007) 956-963. 
[17] I. Danilidis, J.A. Hunter, G.M. Scamans, J.M. Sykes, Effects of inorganic additions on the performance of manganese-based conversion treatments, Cor. Sci. 49 (2007) 1557-1569.

[18] K. Asami, M. Oki, G.E. Thompson, G.C. Wood, V. Ashworth, Composition of the near surface regions on conversion coated aluminum. Electr. Acta. 32(2) (1987) 337-343.

[19] L. Chang-Sheng, Z. Lv, Y. Zhu, S. Xu, Molybdate-based conversion treatment for improving the peeling strength between aluminum foil and polypropylene grafted with glycidyl methacrylate. Surf. Coat. Techn. 249 (2014) 1-5.

[20] M.L. Zheludkevich, I. Miranda Salvadob, M.G.S. Ferreira, Sol-gel coatings for corrosion protection of metals. J. Mat. Chem. 15 (2005) 5099-5111.

[21] M. Oki, Microstructural and compositional characterization of chromate pretreatment on aluminium, ISRN Mat. Sci. 2013, Article ID572379,

[22] G. Yogannadan, J.N. Balaraju, V.K. William Grips, The surface and electrochemical analysis of permanganate based conversion coating on alclad and unclad 2024 alloy. Appl. Sur. Sci. 258 (22) (2012) 8880-8888.

[23] W. Guixiang, Z. Milin, W. Ruizhi, Molybdate and molybdate/permanganate conversion coatings on Mg-8.5Li alloy. Appl. Sur. Sci. 258 (2012) 2648-2654.

[24] M. Oki, A.A. Adediran, S. Olayinka, O. Ogunsola, Development and performance of hybrid coatings on aluminium alloy. J. Electrochem. Sci. Eng. 7 (2017), 131-138. 